\title{
Disruption of a Hydrogen Bond Network in Human versus Spider Monkey Cytochrome $c$ Affects Heme Crevice Stability
}

\author{
Matthew E. Goldes, ${ }^{a}$ Margaret E. Jeakins-Cooley, ${ }^{a}$ Levi J. McClelland, ${ }^{\text {a,b }}$ Tung-Chung Mou, ${ }^{b, c}$ \\ and Bruce E. Bowler*a, \\ ${ }^{a}$ Department of Chemistry and Biochemistry, University of Montana, Missoula, MT 59812 \\ ${ }^{\mathrm{b}}$ Division of Biological Sciences, University of Montana, Missoula, MT 59812 \\ ${ }^{\mathrm{c}}$ Center for Biomolecular Structure and Dynamics, University of Montana, Missoula, MT 59812
}

*Corresponding Author. Tel.: +406 2436114; fax: +406 2434227. Email address:

bruce.bowler@umontana.edu (B. E. Bowler). 


\begin{abstract}
The hypothesis that the recent rapid evolution of primate cytochromes $c$, which primarily involves residues in the least stable $\Omega$-loop $(\Omega$-loop $\mathrm{C}$, residues $40-57)$, stabilizes the heme crevice of cytochrome $c$ relative to other mammals, is tested. To accomplish this goal, we have compared the properties of human and spider monkey cytochrome $c$ and a set of four variants produced in the process of converting human cytochrome $c$ into spider monkey cytochrome $c$. The global stability of all variants has been measured by guanidine hydrochloride denaturation. The stability of the heme crevice has been assessed with the alkaline conformational transition. Structural insight into the effects of the five amino acid substitutions needed to convert human cytochrome $c$ into spider monkey cytochrome $c$ is provide by a $1.15 \AA$ resolution structure of spider monkey cytochrome $c$. The global stability for all variants is near $9.0 \mathrm{kcal} / \mathrm{mol}$ at $25^{\circ} \mathrm{C}$ and $\mathrm{pH} 7$, which is higher than that observed for other mammalian cytochromes $c$. The heme crevice stability is more sensitive to the substitutions required to produce spider monkey cytochrome $c$ with decreases of up to 0.5 units in the apparent $\mathrm{p} K_{\mathrm{a}}$ of the alkaline conformational transition relative to human cytochrome $c$. The structure of spider monkey cytochrome $c$ indicates that the Y46F substitution destabilizes the heme crevice by disrupting an extensive hydrogen bond network that connects three surface loops including $\Omega$-loop D (residues 70-85), which contains the Met80 heme ligand.
\end{abstract}

\title{
Keywords
}

Spider Monkey Cytochrome c; Global stability; Alkaline conformational transition; Heme crevice stability; Hydrogen bond network. 


\section{Introduction}

Cytochrome $c(\mathrm{Cyt} c)$ resides in the intermembrane space of mitochondria. Its function as a component of the electron transport chain has been known for many years $[1,2]$. About 20 years ago, it was discovered that release of Cytc from mitochondria, followed by its interaction with Apaf-1 to form the apoptosome [3,4], is a critical signaling event in the intrinsic pathway of apoptosis [5, 6]. Furthermore, peroxidative activity, particularly directed at the inner mitochondrial membrane lipid, cardiolipin (CL), is believed to be the earliest signal in the intrinsic pathway of apoptosis [7]. More recently it has been postulated that the peroxidase activity of Cytc may provide a rich source of CL-based lipid signaling agents $[8,9]$. The peroxidase activity of Cytc is linked to loss of the Met80-heme bond [5, 6]. Thus, there has been considerable interest recently in the factors that control the stability of the heme crevice [10, 11].

It has been noted recently that there has been a rapid evolution of Cyt $c$ in the primate lineage $[12,13]$. It has been postulated that this evolution may be coupled to evolution of cytochrome $c$ oxidase. However, many of the mutations in the evolution of primate cytochromes $c$ are found in a surface loop, $\Omega$-loop C (residues 40-57), which is believed to modulate the opening of the heme crevice in the alkaline conformational transition [14]. Human Cytc (Hu Cytc) and spider monkey Cytc (SM Cytc) are on different branches of the evolutionary tree of primate cytochromes $c$. Furthermore, it has been postulated that the A50E substitution, found in SM Cyt $c$ relative $\mathrm{Hu} \mathrm{Cyt} c$, may destabilize the heme crevice by providing an electrostatic interaction that can compete with the hydrogen bond between the $\varepsilon$-amino group of Lys 79 and the main chain carbonyl of residue 47 [15].

As an initial test of the hypothesis that the rapid evolution of primate cytochromes $c$ may also affect the stability of the heme crevice and thus could be important for the peroxidase activity of 
Cytc in apoptosis, we have prepared SM Cytc from Hu Cytc in a stepwise manner. There are only five substitutions in the sequence of SM Cytc relative to Hu Cytc [15]. However, four of these substitutions are in $\Omega$-loop C. Here, we characterize the global stability of Hu Cytc, SM Cyt $c$ and the four intermediate variants used to produce SM Cytc from Hu Cytc. To characterize the effects of these substitutions on the stability of the heme crevice, we have measured the alkaline conformational transition of the set of six cytochromes $c$. We also report a $1.15 \AA$ structure of SM Cytc that provides high resolution structural insight into the effects of these mutations on heme crevice stability.

We find that the effects of the five substitutions required to produce SM Cytc from Hu Cytc on the global stability of Cyt $c$ are modest. However, the apparent $\mathrm{p} K_{\mathrm{a}}$ of the alkaline transition is decreased by up to 0.5 units. The Y46F mutation has the largest effect on the alkaline transition. This observation is supported by comparison of our SM Cytc structure with that of Hu Cytc, which shows that the $\mathrm{Y} 46 \mathrm{~F}$ mutation compromises the integrity a hydrogen bond network that holds together three surface loops in the structure of Cytc.

\section{Experimentals}

\subsection{Preparation of the spider monkey cytochrome c expression vector}

The pBTR(HumanCc) plasmid for expression of Hu Cytc in Escherichia coli was provided by Gary Pielak at the University of North Carolina [3]. The pBTR(HumanCc) plasmid is a derivative of the pBTR1 plasmid $[16,17]$ produced by replacing the yeast iso-1-Cytc gene (CYC1) with a synthetic Hu Cytc gene [3, 18]. Thus, the plasmid co-expresses the yeast heme lyase gene (CYC3) permitting covalent attachment of heme in the cytoplasm of E. coli. SM Cyt $c$

differs at five sequence positions from Hu Cytc [15]. The necessary K8R, P44S, Y46F, S47T and A50E mutations were introduced sequentially starting at the $\mathrm{N}$-terminus of the protein using the 
QuikChange PCR-based mutagenesis protocol (Agilent) producing the set of variants K8R, K8R/P44S, K8R/P44S/Y46F, K8R/P44S/Y46F/S47T and finally SM Cytc (K8R/P44S/Y46F/S47T/A50E). The final SM Cytc plasmid pBTR(SMCytc) is available through Addgene (https://www.addgene.org/). Primers used for mutagenesis are listed in Table S1 of the Supplementary Data. Plasmid DNA for each variant was prepared from TG-1 E. coli cells transformed with DNA produced by the QuikChange protocol using the Qiagen miniprep procedure (Qiagen). The entire coding region of the Cytc gene was sequenced at the Murdock DNA Sequencing facility at the University of Montana to confirm the identity of each variant.

\subsection{Expression of Cytc variants}

Cyt $c$ variants were expressed after transformation of the expression plasmid into competent E. coli BL21 DE3 cells (EdgeBio). Transformed cells on agar plates were re-suspended in sterile L-broth $(4 \mathrm{~mL})$ and used to inoculate $1 \mathrm{~L}$ of sterilize $2 x \mathrm{YT}$ broth $\left(1 \mathrm{~L}\right.$ deionized $\mathrm{H}_{2} \mathrm{O}, 16 \mathrm{~g}$ tryptone, $10 \mathrm{~g}$ yeast extract, $5 \mathrm{~g} \mathrm{NaCl})$ in a Fernbach flask. $2 \mathrm{~mL}$ of sterile ampicillin $(100$ $\mathrm{mg} / \mathrm{mL}$ ) was added to each flask. All flasks were grown in an orbital shaker incubator (Thermo Forma 435) at $30^{\circ} \mathrm{C}$ or $37^{\circ} \mathrm{C}$ for $24 \mathrm{~h}$.

After growth, the cells were pelleted using a Sorvall RC 5C+ centrifuge (Thermo) with a GS3 rotor $(5,000 \mathrm{rpm})$ and stored at $-80^{\circ} \mathrm{C}$. Protein was isolated from cell pellets using methods similar to those reported for yeast iso-1-cytochrome $c$ (iso-1-Cytc) [19]. In brief, before mechanically lysing the cells, they were subjected to three freeze-thaw cycles at $-80{ }^{\circ} \mathrm{C}(3 \mathrm{~h})$ and $4{ }^{\circ} \mathrm{C}(2 \mathrm{~h})$, respectively. Cell pellets were then re-suspended in $2 \mathrm{~mL}$ of lysis buffer $(100 \mathrm{mM}$ Tris, $1 \mathrm{mM}$ NaEDTA, $500 \mathrm{mM} \mathrm{NaCl}$, pH 8.0) per gram of cells. A small amount of lyophilized DNase and RNase powder was added along with the protease inhibitor PMSF to a final 
concentration of $3 \mathrm{mM}$. The resuspended cells were then passed through a French Pressure Cell (SLM Aminco) a minimum of four times. The lysed cells were spun down at 10,000 rpm (GSA rotor) in a Sorvall $\mathrm{RC} 5 \mathrm{C}+$ centrifuge for $30 \mathrm{~min}$ and the supernatant was passed through a filter cloth. The supernatant was brought to 50\% saturation with ammonium sulfate and stirred overnight at $4{ }^{\circ} \mathrm{C}$, followed by centrifugation at $10,000 \mathrm{rpm}$ (GSA rotor) to remove precipitated protein impurities. The supernatant was passed through filter cloth and dialyzed against $12.5 \mathrm{mM}$ sodium phosphate, $\mathrm{pH}$ 7.2, $1.0 \mathrm{mM}$ EDTA, $2.0 \mathrm{mM} \beta$-mercaptoethanol. The dialyzed protein was batch loaded onto CM Sepharose fast-flow beads (GE Healthcare) and the resin packed into glass column $(3.2 \mathrm{~cm} \times 18.4 \mathrm{~cm})$ followed by elution of Cytc with a $200 \mathrm{~mL}$ linear gradient from 0 to $0.8 \mathrm{M} \mathrm{NaCl}$ in $50 \mathrm{mM}$ sodium phosphate, $\mathrm{pH} 7.2,1 \mathrm{mM}$ EDTA, $2 \mathrm{mM} \beta$ mercaptoethanol. Cytc containing fractions were exchanged into $50 \mathrm{mM}$ sodium phosphate at $\mathrm{pH}$ 7 (HPLC buffer A) using an Amicon stirred ultrafiltration cell and then concentrated to 1.6 $\mathrm{mg} / \mathrm{mL}$ using centrifuge ultrafiltration. Aliquots of $1.5 \mathrm{~mL}$ were flash frozen and stored at $-80^{\circ} \mathrm{C}$ freezer for later use. Yields of SM Cytc are $9-10 \mathrm{mg}$ per liter of 2x YT culture.

Aliquots were thawed and purified by HPLC using a Bio-Rad UNO S6 column immediately in advance of experiments. The following gradient at a flow rate of $3.0 \mathrm{~mL} / \mathrm{min}$ was used for purification: $0 \% \mathrm{~B}$ from 0 to $7 \mathrm{~min}$, increase to $30 \% \mathrm{~B}$ from 7 to $34 \mathrm{~min}$, maintain $30 \% \mathrm{~B}$ from 34 to 40 min., increase to $100 \%$ B from 40 to $43 \mathrm{~min}$, maintain $100 \%$ B from 43 to $50 \mathrm{~min}$, decrease to $0 \%$ B from 50 to $53 \mathrm{~min}$, maintain $0 \%$ B from 53 to $63 \mathrm{~min}$. HPLC buffer B is HPLC buffer A with 1.0 M NaCl. Pure Cytc fractions were concentrated by ultrafiltration.

The molecular weight of the SM Cytc was measured to be $12,307.7 \mathrm{~g} / \mathrm{mol}\left(\mathrm{M}+\mathrm{H}^{+}\right.$, expected $\mathrm{M}+\mathrm{H}^{+}=12,309.1 \mathrm{~g} / \mathrm{mol}$ ) using a Bruker microflex MALDI-ToF mass spectrometer. Protein Calibration Standard I (Bruker Part No. 206355) was used to calibrate the mass spectrometer. 


\subsection{Oxidization of Cytc}

All experiments were performed on the oxidized state, Fe(III)heme, of Cytc. Potassium ferricyanide was used to oxidize the protein using $5 \mathrm{mg}$ of ferricyanide per $\mathrm{mg}$ of protein. After $15 \mathrm{~min}$ at $4{ }^{\circ} \mathrm{C}$, the Cytc solution was spun in a microcentrifuge for $5 \mathrm{~min}$ and loaded on a column packed with Sephadex G-25 superfine size-exclusion resin. The sephadex G-25 resin was equilibrated and run with the buffer to be used in the experiment.

\subsection{Measurement of global stability by guanidine hydrochloride denaturation}

Circular dichroism (CD) spectroscopy was used to monitor guanidine hydrochloride (GdnHCl) unfolding of Cyt $c$ variants. A $4 \mu \mathrm{M}$ Cyt $c$ sample was prepared in CD Buffer (20 mM Tris, $40 \mathrm{mM} \mathrm{NaCl}$ adjusted to $\mathrm{pH}$ 7.0). A $6 \mathrm{M} \mathrm{GdnHCl}$ solution in $\mathrm{CD}$ Buffer, also containing 4 $\mu \mathrm{M}$ Cyt $c$, was used to titrate the Cyt $c$ sample in $\mathrm{CD}$ buffer. Titrations were carried out at $25^{\circ} \mathrm{C}$ using a Hamilton Microlab 500 titrator interfaced with an Applied Photophysics Chirascan CD spectrophotometer. Data were collected at $222 \mathrm{~nm}$ using $250 \mathrm{~nm}$ as background to account for instrumental drift during the titration.

Plots of background corrected ellipticity at $222 \mathrm{~nm}, \theta_{222 \mathrm{corr}}\left(\theta_{222 \mathrm{corr}}=\theta_{222}-\theta_{250}\right)$, versus $\mathrm{GdnHCl}$ concentration were fit to a linear free energy relationship between the free energy of unfolding, $\Delta G_{\mathrm{u}}$, and $\mathrm{GdnHCl}$ concentration using nonlinear least squares methods (SigmaPlot 7), and Eq. (1) [20], where $\theta_{\mathrm{N}}$ is the ellipticity of the native state of Cytc, $\theta_{\mathrm{D}}$ is the ellipticity of the

$$
\theta_{22 \text { corr }}=\frac{\theta_{\mathrm{N}}+\left[\left(\theta_{\mathrm{D}}+m_{\mathrm{D}}[\mathrm{GdnHCl}]\right) \exp \left\{\frac{m[\mathrm{GdnHCl}]-\Delta G_{\mathrm{u}}^{\circ}\left(\mathrm{H}_{2} \mathrm{O}\right)}{\mathrm{RT}}\right\}\right]}{1+\exp \left\{\frac{m[\mathrm{GdnHCl}]-\Delta G_{\mathrm{u}}^{\circ}\left(\mathrm{H}_{2} \mathrm{O}\right)}{\mathrm{RT}}\right\}}
$$


denatured state extrapolated to $0 \mathrm{M} \mathrm{GdnHCl}, m_{\mathrm{D}}$ is the slope of the denatured state baseline as a function of $\mathrm{GdnHCl}$ concentration, $\Delta G_{\mathrm{u}}{ }^{\mathrm{o}}\left(\mathrm{H}_{2} \mathrm{O}\right)$ is $\Delta G_{\mathrm{u}}$ extrapolated to $0 \mathrm{M} \mathrm{GdnHCl}$ and $m$ is the slope of $\Delta G_{\mathrm{u}}$ as a function $\mathrm{GdnHCl}$ concentration.

\subsection{Measurement of local stability via the alkaline conformational transition}

The alkaline conformation transition of the Cytc variants was measured by $\mathrm{pH}$ titration monitored at $695 \mathrm{~nm}$, an absorbance band sensitive to Met80-hemeFe(III) ligation [2, 21, 22]. A $400 \mu \mathrm{M}$ protein in $200 \mathrm{mM} \mathrm{NaCl}$ solution (2x-stock) was mixed 1:1 with deionized water to make the titration solution ( $200 \mu \mathrm{M}$ Cytc in $100 \mathrm{mM} \mathrm{NaCl})$. An equal volume of $\mathrm{HCl}$ solution and the $2 \mathrm{x}$-stock was added to adjust the titration solution to about $\mathrm{pH}$ 6.3. For each step of the titration, equal volumes of an $\mathrm{NaOH}$ solution of appropriate concentration and of the $2 \mathrm{x}$-stock solution were added to raise the $\mathrm{pH}$ of the titration solution by $0.15-0.20 \mathrm{pH}$ units. The $\mathrm{pH}$ was recorded with a semimicro calomel electrode and the spectrum was recorded from 750 to $500 \mathrm{~nm}$ at each step. The titration was continued until a pH of 11 was achieved. Titrations were carried out at room temperature, $23 \pm 1{ }^{\circ} \mathrm{C}$.

The absorbance at $750 \mathrm{~nm}, \mathrm{~A}_{750}$, was subtracted from the absorbance at $695 \mathrm{~nm}, \mathrm{~A}_{695}$, to correct for instrumental drift during the titration. The corrected absorbance at $695 \mathrm{~nm}, \mathrm{~A}_{695 \mathrm{corr}}$ $\left(\mathrm{A}_{695 \mathrm{corr}}=\mathrm{A}_{695}-\mathrm{A}_{750}\right)$, was plotted against $\mathrm{pH}$ and fit to a modified form of the HendersonHasselbalch equation, Eq. (2), which accounts for the number of protons linked to the alkaline transition, $n$.

$$
\mathrm{A}_{695 \mathrm{corr}}=\frac{\mathrm{A}_{\mathrm{N}}+\mathrm{A}_{\mathrm{alk}} \times 10^{n\left(\mathrm{p} K_{\mathrm{app}}-\mathrm{pH}\right)}}{1+10^{n\left(\mathrm{pK} K_{\text {app }}-\mathrm{pH}\right)}}
$$


Fits were carried out using nonlinear least squares methods (SigmaPlot 7) yielding, $n$ and the apparent $\mathrm{p} K_{\mathrm{a}}, \mathrm{p} K_{\mathrm{app}}$, of the alkaline conformational transition.

\subsection{Ionic strength dependence of the alkaline conformational transition of SM Cytc}

The methods of Osheroff et al. [15] were used to carry out measurement of the alkaline conformational transition as a function of ionic strength. A $25 \mathrm{mM}$ Tris/acetate buffer, $\mathrm{pH} 7.0$, stock buffer was prepared by titrating acetic acid with $1 \mathrm{M}$ Tris base solution until a $\mathrm{pH}$ of 7 was achieved. The buffer was adjusted to its final volume in a volumetric flask such that the concentration of acetate was $25 \mathrm{mM}$. For $\mathrm{pH}$ titrations with $\mathrm{NaOH}$, each Tris $\mathrm{H}^{+}$titrated by $\mathrm{NaOH}$ is replace by $\mathrm{Na}^{+}$, so the ionic strength does not change with $\mathrm{pH}$. This buffer was diluted to $10 \mathrm{mM}$ for oxidation of SM Cytc and separation of oxidized protein from ferricyanide by Sephadex G25 chromatography. To increase the ionic strength of the solution, $\mathrm{NaCl}$ was added to create the desired solution ionic strength. Titrations were carried out and data were analyzed as described in section 2.5 .

\subsection{Crystallization, data collection, and structure determination of SM Cytc}

The isolated SM Cytc protein was concentrated to $37 \mathrm{mg} / \mathrm{ml}$ by centrifuge ultrafiltration in a buffer of $50 \mathrm{mM}$ Tris.HCl, $\mathrm{pH}$ 7. The initial crystallization condition was obtained by commercial crystallization screening trials. Additional vapor diffusion crystallization experiments were set up in grid screening by expanding the $\mathrm{pH}$ range and precipitant concentrations in 24-well VDX plates. After 2 to 4 weeks of equilibration at $20{ }^{\circ} \mathrm{C}$, large cubicshaped crystals were obtained by mixing $1 \mu \mathrm{L}$ of protein with an equal volume of $0.1 \mathrm{M} \mathrm{LiCl}$, 20\% PEG 6000, 0.1 M HEPES sodium salt, pH 8.2, reservoir solution. For cryoprotection, 
crystals were transferred into reservoir solution containing 30\% (v/v) PEG 400 and flash-frozen in a $100 \mathrm{~K}$ nitrogen gas stream.

Diffraction data were collected at the Stanford Synchrotron Radiation Lightsource SSRLSMB 14-1 beamline using a MAR325 CCD detector at an incident beam wavelength of $1.22 \AA$. Images were indexed, integrated, and scaled using HKL2000 [23]. The initial phasing map was determined by molecular replacement with Phaser, integrated in the PHENIX software suite [24], using the coordinates of yeast iso-1-Cytc (PDB 2YCC) as a search model, against 8 to $2 \AA$ experimental data. A continuous electron density map with a clearly defined protein-solvent boundary was observed. The initial model was first subjected to one cycle of rigid-body refinement using PHENIX. Subsequently, the model was further refined by iterative model rebuilding with COOT [25] and refinement of atomic positions, real space, occupancy, and isotropic B-factor parameters with PHENIX using a subset of reflections for calculation of $\mathrm{R}_{\text {free }}$ (Table 1). At a later stage of refinement, the refined structure was improved to a final resolution of $1.15 \AA$ and the coordinates of hydrogen atoms were included in the subsequent refinement cycles. Data collection and refinement statistics of the final model are shown in Table 1. The coordinates and structure factors for spider monkey Cytc have been deposited in the Protein Data Bank (PDB) under the ID code: 5DFS.

\section{Results and Discussion}

\subsection{Global Stability of Human and Spider Monkey Cytc}

Spider monkey cytochrome $c$, SM Cytc, has five substitutions relative to Human Cytc, Hu Cytc. Most of these substitutions occur in the $\Omega$-loop that runs from residues 40 to 57 ( $\Omega$-loop C). The sole substitution outside of this region is in the N-terminal helix, a K8R substitution. We 
made this conservative mutation first expecting that its effect on stability would be modest. The remaining four substitutions occur in a short sequence segment from residues 44 to 50 . Based on native-state hydrogen-deuterium exchange (NSHX) studies on equine Cytc and limited proteolysis on yeast iso-1-Cytc, this $\Omega$-loop is the least stable part of mitochondrial Cytc [26, 27]. Thus, changes in stability are expected to propagate upward affecting the global stability of Hu Cyt $c$ versus SM Cytc [28, 29]. Mutations were made sequentially starting at position 44 and ending with the position 50 substitution (A50E).

To assess the effect of each mutation on global stability we carried out $\mathrm{GdnHCl}$ denaturation of each protein. The unfolding titration curves for Hu Cyt, SM Cytc and the four intervening variants are shown in Fig. 1. It is evident from the $\mathrm{GdnHCl}$ denaturation data that the unfolding midpoint concentration, $C_{\mathrm{m}}$, for all six sequence variants of Cytc is similar. The $\Delta \mathrm{G}_{\mathrm{u}}{ }^{\mathrm{o}}\left(\mathrm{H}_{2} \mathrm{O}\right)$ of $8.9 \pm 0.2 \mathrm{kcal} / \mathrm{mol}$ (Table 2) that we observe for the Hu Cytc, is similar to global stability of $8.7 \mathrm{kcal} / \mathrm{mol}$ at $298 \mathrm{~K}$ reported for $\mathrm{Hu} \mathrm{Cyt} c$ based on thermal denaturation data [3]. Our GdnHCl data also indicate that $\mathrm{Hu} \mathrm{Cyt} c$ is more stable that equine or bovine $\mathrm{Cyt} c$ as determined by $\mathrm{GdnHCl}$ denaturation methods (Table 2). Thermal denaturation data also show that Hu Cytc is more stable than equine Cytc (stability $\sim 6.6 \mathrm{kcal} / \mathrm{mol}$ at $298 \mathrm{~K}$, see ref. [3]). Table 2 shows that SM Cytc and the set of variants used to produce SM Cytc from Hu Cytc all have global stability similar to Hu Cytc.

$\mathrm{Hu}$ Cytc and SM Cytc and the set of variants used to convert Hu Cytc to SM Cyt $c$ also have similar denaturant $m$-values of $\sim 3.5 \mathrm{kcal} \mathrm{mol}^{-1} \mathrm{M}^{-1}$. These values are higher than observed for equine and bovine Cytc but smaller than observed for yeast iso-1-Cytc. Analysis of the denaturant dependence of the stability of the substructures of equine Cytc derived from NSHX studies shows that there is a significant population of intermediates in the transition region for 
GdnHCl unfolding of equine Cytc [30]. The lower GdnHCl $m$-value for equine Cytc (Table 1, see ref. [31]) versus Hu and SM Cytc is consistent with a greater population of intermediates during global unfolding of equine Cytc than for primate cytochromes $c$. Limited proteolysis studies on yeast iso-1-Cytc show that the least stable substructure is close to the global stability of iso-1-Cytc [27]. The $m$-value of iso-1-Cytc [32] is larger than for Hu and SM Cytc, indicating that population of intermediates is less during global unfolding of yeast than for the primate cytochromes $c$. Thus, the intermediate magnitude of the $m$-value for Hu and SM Cytc relative to equine and yeast suggests that the free energy required to unfold the least stable substructure of $\mathrm{Hu}$ and SM Cytc is greater than for equine Cytc.

\subsection{Alkaline conformational transition of Hu and SM Cytc.}

The alkaline conformational transition of oxidized, Fe(III)heme, Cytc occurs at mildly alkaline $\mathrm{pH}[2,33]$. It involves replacement of the native state heme ligand, Met80, with lysine side chains from $\Omega$-loop D (residues 70-85), altering the structure of this $\Omega$-loop [34, 35]. The alkaline conformational transition correlates well with the stability of the unstable substructure of Cytc corresponding to $\Omega$-loop D [36] and thus is often used as a proxy for the stability of the heme crevice. Hydrogen exchange methods indicate that the rate of the alkaline conformational transition is limited by opening of $\Omega$-loop C (residues 40-57) the least stable substructure of mitochondrial cytochromes $c[26,27]$. Thus, the substitutions in this region required to convert Hu to SM Cytc might be expected to affect the alkaline conformational transition.

Fig. 2 shows that, unlike global stability, the local stability of $\Omega$-loop $D$ is sensitive to

mutations in $\Omega$-loop C. The magnitude of $\mathrm{p} K_{\text {app }}$ for Hu Cytc and the K8R and K8R/P44S variants is within error unchanged (Table 3). However, addition of the Y46F mutation leads to a 
significant decrease of 0.4 units in $\mathrm{p} K_{\text {app }}$ relative to Hu Cytc. There is a small additional decrease in $\mathrm{p} K_{\text {app }}$ when the $\mathrm{S} 47 \mathrm{~T}$ mutation is added. The combined effect these two mutations leads to a destabilization of $0.66 \mathrm{kcal} / \mathrm{mol}$ of the native state of $\mathrm{Hu}$ Cytc relative to its alkaline conformer. The final mutation (A50E), producing SM Cytc, partially reverses the destabilizing effect of the Y46F and S47T mutations on the native state relative to the alkaline state of Cytc. Thus, the net destabilization of the native state relative to the alkaline state for SM versus Hu Cytc is only $\sim 0.3$ $\mathrm{kcal} / \mathrm{mol}\left(\Delta \Delta \mathrm{G}_{\mathrm{alk}}=\ln (10) \mathrm{RT} \Delta \mathrm{p} K_{\mathrm{app}}\right)$.

There are a number of measurements of the $\mathrm{p} K_{\text {app }}$ for the alkaline conformational transition of Hu Cytc available in the literature. Margoliash and coworkers reported the $\mathrm{p} K_{\text {app }}$ of Hu Cytc isolated from human heart (with $\mathrm{N}$-terminal acetylation) as 9.50 at $10 \mathrm{mM}$ ionic strength rising to 9.85 at 250 and $500 \mathrm{mM}$ ionic strength. Our $\mathrm{p} K_{\text {app }}$ of 9.54 obtained at $\sim 100 \mathrm{mM}$ ionic strength falls in the middle of this range as would be expected. Under similar conditions, equine Cytc has a p $K_{\text {app }} \sim 0.4$ to 0.45 units lower [15]. Thus, the lower global stability of equine Cytc relative to $\mathrm{Hu}$ Cytc is correlated with lower stability of the heme crevice as measured by the alkaline conformational transition. Other reported values for the $\mathrm{p} K_{\text {app }}$ of Hu Cyt $c$ are for E. coliexpressed $\mathrm{Hu}$ Cytc (not $\mathrm{N}$-terminally acetylated) and range from 9.0 to 9.9 [37-41]. The $\mathrm{p} K_{\text {app }}$ of Cytc is sensitive to ionic strength and specific ion interactions $[15,42,43]$. Some of this observed range likely results from specific anion binding effects due to phosphate and citrate in the titration buffers used.

For Hu Cytc, the $\mathrm{p} K_{\text {app }}$ for a $\mathrm{Y} 46 \mathrm{~F}$ variant has been reported. Relative to the value reported for Hu Cytc, the $\mathrm{p} K_{\text {app }}$ decreases by $\sim 0.6$ units for the $\mathrm{Y} 46 \mathrm{~F}$ variant, similar the $\sim 0.4$ unit decrease in $\mathrm{p} K_{\text {app }}$ we observe when the $\mathrm{Y} 46 \mathrm{~F}$ mutation is added to the $\mathrm{K} 8 \mathrm{R} / \mathrm{P} 44 \mathrm{~S}$ variant (Table $3)$. 
Hu Cytc and the K8R and K8R/P44S all have alkaline conformational transitions consistent with the release of a single proton $(n=1$, see Table 3$)$ being linked to the conformational change. After addition of the Y46F mutation, $n$ drops to $\sim 0.9$. The decrease in $n$ may reflect a change in coupling of protonation equilibria to the alkaline conformational transition, which have been shown to be complex in this $\mathrm{pH}$ regime [44-46]. It may also reflect mutation-induced changes in the $\mathrm{p} K_{\mathrm{a}}$ of one of the lysine ligands contributing to the alkaline state leading to a broadening of the transition $[47,48]$.

\subsection{Ionic strength dependence of $p K_{a p p}$}

The $\mathrm{p} K_{\text {app }}$ of $9.32 \pm 0.03$ we observed for SM Cytc in $0.1 \mathrm{M} \mathrm{NaCl}$ is similar to the $\mathrm{p} K_{\text {app }}$ of 9.3 observed by Margoliash and coworkers in the presence of $0.25 \mathrm{M}$ sodium acetate [15]. However, at low ionic strength (10 $\mathrm{mM}$ Tris acetate $\mathrm{pH} 7)$ the $\mathrm{p} K_{\text {app }}$ observed by Margoliash and coworkers decreased to 8.70 [15]. They proposed that the large decrease in the $\mathrm{p} K_{\text {app }}$ observed for SM Cytc was due to an electrostatic interaction between Glu50 and Lys79 competing with the heme crevice stabilizing hydrogen bond between the carbonyl-O of residue 47 and the $\varepsilon$ amino group of Lys79. The observation that the A50E mutation partially reverses the effect of the Y46F and S47T mutations appears at odds with this proposal. Therefore, we studied the ionic strength dependence of the $\mathrm{p} K_{\text {app }}$ of SM Cytc.

In $10 \mathrm{mM}$ Tris acetate, we find that the $\mathrm{p} K_{\text {app }}$ of $E$. coli-expressed SM Cytc is similar to that observed in $100 \mathrm{mM} \mathrm{NaCl}$ and about 0.5 units higher that observed for SM Cytc obtained from its natural source (Table 4). Addition of $\mathrm{NaCl}$ to $10 \mathrm{mM}$ Tris acetate to raise the ionic strength to $50 \mathrm{mM}$ and $250 \mathrm{mM}$ has only modest effects on the $\mathrm{p} K_{\text {app }}$. The large difference in the $\mathrm{p} K_{\text {app }}$ in $10 \mathrm{mM}$ Tris acetate for SM Cytc expressed from E. coli versus from its natural source, points to 
the N-terminal acetylation of SM Cyt $c$ from its native source as a possible cause for the observed difference.

It has been shown that phosphate, but not acetate, can strongly increase the intensity of the $695 \mathrm{~nm}$ absorbance band suggesting that phosphate can strengthen the heme-Met80 bond [49]. While acetate binds only weakly to cytochrome $c$ [42], both phosphate and chloride [50] bind specifically. Thus, as a control experiment the effect of increasing $\mathrm{Cl}^{-}$concentration on the 695 $\mathrm{nm}$ absorbance band of SM Cytc was monitored. In contrast to phosphate binding to horse Cytc [49], no significant effect is observed from 0 to $250 \mathrm{mM} \mathrm{Cl}^{-}$on the magnitude of the extinction coefficient at $695 \mathrm{~nm}$ (Fig. S1). Thus, $\mathrm{Cl}^{-}$does not appear to directly affect the strength of the heme-Met80 bond for SM Cytc.

Interestingly, there is a drop in the number of protons, $n$, linked to the alkaline conformational transition at ionic strengths of $10 \mathrm{mM}$ and $50 \mathrm{mM}$ by $\sim 0.1$ relative to the $n$ observed in $100 \mathrm{mM} \mathrm{NaCl}$ and at an ionic strength of $250 \mathrm{mM}$ (Tables 3 and 4). It has also been shown that the alkaline transition is less cooperative at low ionic strength for horse Cytc [45]. Loss of cooperativity can be achieved if the alkaline transition involves two ionizable ligands, where one of the ionizable ligands has a significantly lower $\mathrm{p} K_{\mathrm{a}}$ than the other ligand but does not drive the alkaline transition to completion [51]. Fig. S2 demonstrates that an equally good fit to the data as with Eq. (2) can be achieved at low ionic strength with this model assuming that there are two lysine ligands for the alkaline state with significantly different $\mathrm{p} K_{\mathrm{a}}$ values [47]. The N-terminal amino group of E. coli-expressed horse Cyt $c$ can participate in the alkaline conformational transition [36]. Thus, we cannot rule out the N-terminal amino group as a ligand in the alkaline state. 


\subsection{High resolution X-ray structure of SM Cytc.}

To gain insight into the differences in the alkaline conformational transition between $\mathrm{Hu}$ Cytc and SM Cytc we prepared crystals of SM Cytc. The crystals diffracted to $1.15 \AA$ A resolution providing a high quality structural model for SM Cytc $\left(R_{\text {work }}=0.159 ; R_{\text {free }}=0.182 ;\right.$ see Table 1$)$. Fig. 3 shows the electron density around the heme including the hydrogen bonding network that includes Tyr67, Asn52, Thr78 and a buried water molecule, showing the high quality of the electron density map and its fit to the model. There are two molecules of SM Cytc (chains A and B) in the asymmetric unit, which align with a $\mathrm{C}_{\alpha}$ RMS deviation of $0.385 \AA$. There are different conformers for 17 side chains in the two molecules of the asymmetric unit. Most of these are at solvent exposed sites. Two side chains in chain A and four in chain B were fit to two rotamers. Only Arg91 has two rotamers in both chains. Several of these alternate side chain conformers will be highlighted in the discussion that follows.

Buried water molecules are characteristic of mitochondrial cytochromes $c$ [52]. There are three buried water molecules in chain A and six in chain B. Two of the additional buried waters in chain B are near the surface and result from alternate conformers of the His 33 and Asn103 side chains in chain A versus $\mathrm{B}$. One buried water molecule (B-factor $=10.35 \AA^{2}$, chain $\mathrm{A}$ ) is hydrogen bonded to Asn52, Tyr67 and Thr78 and is observed for both chains (Fig. 3 and Fig. 4). This water has been implicated in redox function $[52,53]$. A second buried water molecule (Bfactor $=10.84 \AA^{2}$, chain A) is hydrogen bonded to heme propionate A, main chain atoms of Lys39 and Gln42 and the side chain of Arg38 (Fig. 4). This water is believed to be important for holding Arg38 against the heme, allowing Arg38 to regulate the heme redox potential by chargecharge interactions [54]. Recent structural studies on an alternate conformer of K72A iso-1-Cytc show that the Arg38 side chain can gate access of water to the heme crevice, perhaps mediating 
general acid/base catalysis during peroxidase activity associated with apoptosis [11]. These two buried waters are broadly conserved in mitochondrial cytochromes $c$ and as indicated above may be important for function $[52,53]$. A third buried water (B-factor $=9.29 \AA^{2}$, chain A) hydrogen bonded to main atoms of Thr19, Lys25, Lys27, and Gly29 and the side chain of Thr19 sits near the heme ligand His 18 and may help to stabilize a tight turn [55]. The remaining buried water is only observed in chain B and is hydrogen bonded to heme propionate A, the main chain of Asn31 and the side of Arg38. This water is observed in yeast iso-1-Cytc [52, 56, 57], but not in horse [53, 55] and human [41] Cytc (Fig. S3).

As can be seen in Fig. 4, the structures of SM Cytc and Hu Cytc overlay well $\left(\mathrm{C}_{\alpha}\right.$ RMSD of $0.390 \AA$, chain A versus chain A). The main chain overlays nearly perfectly with small deviations near the P44S substitution, in the single turn of helix running from residues 49 to 56 and near Gly77 in $\Omega$-loop D. The rotamers of the side chains at the positions of the substituted side chains P44S (in chain B a different rotamer is observed, Fig. S3), Y46F and S47T are surprisingly similar. The surface substitutions, $\mathrm{K} 8 \mathrm{R}$ and $\mathrm{A} 50 \mathrm{E}$, have similar $\mathrm{C}_{\beta}$ positions. The small main chain deviation in the short 50's helix leads to an alternate rotamer for Asn52 (Fig. 4) that significantly lengthens the hydrogen bonds to the buried water adjacent to Met80 relative to those observed in chain B where the same rotamer of Asn52 as for Hu Cytc is observed (Fig. 4 versus Fig. S3). For chain B of SM Cytc, the main chain deviations near the P44S substitution are smaller relative to Hu Cytc, and similar in the short 50's helix. However, the displacement of $\Omega$-loop D in chain B of SM Cytc relative to Hu Cytc occurs primarily after Met80 (Fig. S3). Thus, while different in detail, both molecules of SM Cytc, show structural deviations that might affect the stability of $\Omega$-loop D. 
The A50E mutation has been proposed to provide an electrostatic interaction with Lys79 which competes with a hydrogen bond from the $\varepsilon$-amino group of Lys79 to the main chain carbonyl of residue 47 . This hydrogen bond is believed to stabilize the heme crevice and thus the A50E mutation in SM Cytc is believed to explain the low $\mathrm{p} K_{\text {app }}$ for SM Cytc relative to Hu Cytc. Our structural data show that Glu50 forms an electrostatic contact with Lys53 (Fig. 4). Thus, the effect of the A50E mutation on heme crevice stability may be only indirect, leading instead to subtle adjustments to the main chain of the 50's helix as described above.

The $\mathrm{Y} 46 \mathrm{~F}$ mutation introduces the largest decrease in the $\mathrm{p} K_{\text {app }}$ of the alkaline transition as Hu Cytc is converted toward SM Cytc (Table 2). In Hu Cytc, Tyr46 is part of a hydrogen bond network that knits together three different surface $\Omega$-loops (Fig. 5). The hydroxyl group of Tyr46 is hydrogen bonded to the carbonyl-O of Thr28. The $\varepsilon$-amino group of Lys79 is hydrogen bonded to the main chain carbonyl-O of Ser47 and to the Thr28 carbonyl-O through two bridging water molecules. In SM Cytc, the Y46F substitution causes loss of the hydrogen bond to the Thr28 carbonyl-O. Loss of this contact destabilizes the Lys79 $\varepsilon$-amino group to Thr28 carbonyl-O water-bridge causing Lys79 to adopt two conformations in chain A (Fig. 5). In one conformer (44\% occupancy), the Lys79 $\varepsilon$-amino group to Thr47 carbonyl-O interaction is maintained and a new hydrogen bond to heme propionate $\mathrm{D}$ is formed. In the other conformer (56\% occupancy), Lys79 projects into the solvent. In Chain B of SM Cytc, the conformation of Lys79 is similar to that in Hu Cytc. However, loss of the Tyr46 hydroxyl to Thr28 carbonyl-O hydrogen bond causes the Lys79 to Thr28 carbonyl-O water-bridge to be less optimal (Fig. S4). Inspection of the structure of the Y46F variant of Hu Cytc [41], shows that the water bridge from the $\varepsilon$-amino group of Lys 79 to the Thr 28 carbonyl-O is disrupted, in addition to the loss of the Tyr46 hydroxyl to Thr28 carbonyl-O hydrogen bond (Fig. S5). Thus, the Y46F substitution 
observed in SM Cytc appears to have a general destabilizing effect on the hydrogen bond network connecting the $\Omega$-loops of Cytc.

We also noted differences in anion binding for the two molecules in the asymmetric unit of SM Cytc. Chain B has no chloride bound (Fig. 6A). Chain A has two chlorides bond, one at the N-terminal end of the 60's helix and the other at the N-terminal end of the short 50's helix (Fig. $6 \mathrm{~B})$. Both presumably interact with the positive end of the helix dipole of these helices. There are no electrostatic interactions at distances of $\sim 5 \AA$ or less for the $\mathrm{Cl}^{-}$near the short 50's helix. The presence of these two different molecules in the asymmetric unit of our structure allows comparisons that may aid in understanding the lack of dependence of $\mathrm{p} K_{\text {app }}$ for the alkaline transition of E. coli-expressed SM Cyt $c$ on $\mathrm{NaCl}$ concentration. Interpretation of the position of surface side chains, necessary for the following analysis, must be approached with caution because often electron density is missing for outer atoms of long side chains at the protein surface and the effects of packing constraints are difficult to assess. The high resolution of the current structure provides a high quality electron density map (Fig. 3). Good electron density is observed for the surface Glu and Asp side chains discussed below. The surface Lys side chains, discussed below, have good electron density out to at least the $\gamma$-carbon. Still, the limitations of the following discussion should be kept in mind.

The $\mathrm{Cl}^{-}$at the N-terminus of the 60's helix of chain B of SM Cytc forms a triad of close electrostatic interactions with Lys99 and Glu61 (Fig. 6B). Although Glu61 is 6.7 (chain B, with $\mathrm{Cl}^{-}$) to $7.0 \AA$ (chain $\mathrm{A}$, no $\mathrm{Cl}^{-}$) from the $\mathrm{N}$-terminal amino group, the binding of $\mathrm{Cl}^{-}$at the $\mathrm{N}$ terminus of the 60's helix appears to affect the balance of electrostatic interactions around the Nterminal amino group. The main result is a substantial shift in the position of the side chain of Glu89. In the absence of $\mathrm{Cl}^{-}$, Glu89 is part of a five-residue salt bridge network with the N- 
terminal amino group, Asp93, Lys5 and Lys87. In the presence of $\mathrm{Cl}^{-}$, Glu89 forms a three-way salt bridge with Lys87 and Glu90. The change in the position of Lys87 caused by this three-way salt bridge moves the main chain sufficiently that a hydrogen bond between the carbonyl of Lys86 and the side chain of Arg91, present in the absence of $\mathrm{Cl}^{-}$(Fig. 6A), is broken (Fig. 6B, see also Fig. 6, caption). This small change in turn affects the electrostatic interactions of Glu69. In the absence of $\mathrm{Cl}^{-}$, Glu69 forms a salt bridge with Lys86 instead of Arg91. The change in the position of Glu69 in the absence of $\mathrm{Cl}^{-}$places it $5.6 \AA$ from Lys73 $(2.1 \AA$ closer than in the presence of $\mathrm{Cl}^{-}$).

The binding of $\mathrm{Cl}^{-}$should stabilize the native state of SM Cytc. Since $\Omega$-loop C controls the opening of $\Omega$-loop D in the alkaline transition [14], stabilization of $\Omega$-loop $\mathrm{C}$ by $\mathrm{Cl}^{-}$binding to the short 50's helix should increase the $\mathrm{p} K_{\text {app }}$ of the alkaline transition as $\mathrm{Cl}^{-}$concentration increases. However, the increase in the distance of Glu69 from $\mathrm{Lys}_{73}$ when $\mathrm{Cl}^{-}$binds should decrease the $\mathrm{p} K_{\mathrm{a}}$ of the alkaline state ligand, Lys73, which should decrease $\mathrm{p} K_{\mathrm{app}}$. These opposing effects of $\mathrm{Cl}^{-}$binding to SM Cytc may explain the insensitivity of the $\mathrm{p} K_{\text {app }}$ of $E$. coliexpressed SM Cytc to increasing $\mathrm{NaCl}$ concentration.

The electrostatic network mediated by the N-terminal amino group of E. coli-expressed SM Cyt $c$ in the absence of $\mathrm{Cl}^{-}$, places Lys73 in a more negative charge environment that would raise its $\mathrm{p} K_{\mathrm{a}}$ and thus the $\mathrm{p} K_{\mathrm{app}}$ of the Lys73-mediated alkaline transition. This effect of the $\mathrm{N}$-terminal amino group could provide an explanation for the higher $\mathrm{p} K_{\mathrm{app}}$ at low ionic strength observed for E. coli-expressed SM Cytc relative to SM Cytc isolated from its natural source with an acetylated N-terminus (Table 4). In the five-residue salt bridge network in Fig. 6A, Glu89 and Asp93 are within $4.4 \AA$ of each other. An acetylated N-terminal amino group could not provide a positive charge to help mitigate the close approach of Glu89 and Asp93. Thus, the position of Glu89 in 
the five-residue salt bridge network observed in the absence of $\mathrm{Cl}^{-}$would be expected to be considerably less favorable with an acetylated N-terminal amino group. Thus, an acetylated Nterminus might favor the less negative electrostatic environment for Lys73 (Fig. 6B), depressing its $\mathrm{p} K_{\mathrm{a}}$ at lower ionic strength and thus contributing to the lower $\mathrm{p} K_{\mathrm{app}}$ of the alkaline transition of SM Cytc from its natural source (Table 4).

\section{Conclusion}

The recent rapid evolution of primate cytochromes $c$ has been attributed primarily to coevolution with cytochrome $c$ oxidase $[12,13]$. In this study, we have shown that the stability of the heme crevice may also be affected on different branches of the primate evolutionary tree. This destabilization may have implications for the peroxidase function of Cytc early in apoptosis. Previous work has suggested that the A50E substitution in SM Cytc versus Hu Cytc destabilizes the heme crevice by causing competition for the heme crevice stabilizing hydrogen bond between the $\varepsilon$-amino group of Lys79 and main chain carbonyl-O of residue 47. Our work shows that the primary effect on heme crevice destabilization is due to the Y46F substitution in SM Cytc versus Hu Cytc. Our high resolution structure of SM Cytc suggests that loss of the Tyr46 hydroxyl to Thr28 carbonyl-O hydrogen bond and of a water bridge that connects the $\varepsilon$-amino group of Lys79 to the Thr28 carbonyl-O are the primary structural factors which lead to heme crevice destabilization.
Abbreviations
Cytc cytochrome $c$
Hu Cytc Human cytochrome $c$ 


$\begin{array}{ll}\text { iso-1-Cyt } c & \text { yeast iso-1-cytochrome } c \\ \mathrm{SM} \mathrm{Cyt} c & \text { spider monkey cytochrome } c \\ \mathrm{GdnHCl} & \text { guanidine hydrochloride } \\ \mathrm{NSHX} & \text { native-state hydrogen-deuterium exchange } \\ \mathrm{p} K_{\text {app }} & \text { apparent } \mathrm{p} K_{\mathrm{a}} \text { of the alkaline conformational transition }\end{array}$

\section{Acknowledgements}

This research was supported by National Science Foundation grants, CHE-0910616 and CHE-

1306903 (B.E.B.). B.E.B. acknowledges support from CoBRE grant P20GM103546 from

NIGMS. The Bruker microflex MALDI-ToF mass spectrometer was purchased with support

from NSF Major Research Instrumentation Grant CHE-1039814.

\section{References}

[1] D.R. Winge, Mol. Cell. Biol. 32 (2012) 2647-2652.

[2] G.R. Moore, G.W. Pettigrew, Cytochromes $c$ : Evolutionary, Structural and Physicochemical Aspects (1990).

[3] A. Olteanu, C.N. Patel, M.M. Dedmon, S. Kennedy, M.W. Linhoff, C.M. Minder, P.R. Potts, M. Deshmukh, G.J. Pielak, Biochem. Biophys. Res. Commun. 312 (2003) 733-740.

[4] T. Yu, X. Wang, C. Purring-Koch, Y. Wei, G.L. McLendon, J. Biol. Chem. 276 (2001) 13034-13038.

[5] Y.P. Ow, D.R. Green, Z. Hao, T.W. Mak, Nat. Rev. Mol. Cell Biol. 9 (2008) 532-542. 
[6] V.E. Kagan, H.A. Bayir, N.A. Belikova, O. Kapralov, Y.Y. Tyurina, V.A. Tyurin, J. Jiang, D.A. Stoyanovsky, P. Wipf, P.M. Kochanek, J.S. Greenberger, B. Pitt, A.A. Shvedova, G. Borisenko, Free Radical Biol. Med. 46 (2009) 1439-1453.

[7] V.E. Kagan, V.A. Tyurin, J. Jiang, Y.Y. Tyurina, V.B. Ritov, A.A. Amoscato, A.N. Osipov, N.A. Belikova, A.A. Kapralov, V. Kini, I.I. Vlasova, Q. Zhao, M. Zou, P. Di, D.A. Svistunenko, I.V. Kurnikov, G.G. Borisenko, Nat. Chem. Biol. 1 (2005) 223-232.

[8] V.E. Kagan, C.T. Chu, Y.Y. Tyurina, A. Cheikhi, H. Bayira, Chem. Phys. Lipids 179 (2014) 64-69.

[9] Y.Y. Tyurina, S.M. Poloyac, V.A. Tyurin, A.A. Kapralov, J. Jiang, T.S. Anthonymuthu, V.I. Kapralova, A.S. Vikulina, M.-Y. Jung, M.W. Epperly, D. Mohammadyani, J. KleinSeetharaman, T.C. Jackson, P.M. Kochanek, B.R. Pitt, J.S. Greenberger, Y.A. Vladimirov, H. Bayır, V.E. Kagan, Nature Chemistry 6 (2014) 542-552.

[10] S. Bandi, B.E. Bowler, Biochemistry 54 (2015) 1729-1742.

[11] L.J. McClelland, T.-C. Mou, M.E. Jeakins-Cooley, S.R. Sprang, B.E. Bowler, Proc. Natl. Acad. Sci. U.S.A. 111 (2014) 6648-6653.

[12] D. Pierron, D.E. Wildman, M. Hütteman, T. Letellier, L.I. Grossman, Adv. Exp. Med. Biol. 748 (2012) 185-213.

[13] D. Pierron, J.C. Opazo, M. Heiske, Z. Papper, M. Uddin, G. Chand, D.E. Wildman, R. Romero, M. Goodman, L.I. Grossman, PLoS ONE 6 (2011) e26269.

[14] L. Hoang, H. Maity, M.M. Krishna, Y. Lin, S.W. Englander, J. Mol. Biol. 331 (2003) 37-43.

[15] N. Osheroff, D. Borden, W.H. Koppenol, E. Margoliash, J. Biol. Chem. 255 (1980) 16891697.

[16] F.I. Rosell, A.G. Mauk, Biochemistry 41 (2002) 7811-7818.

[17] W.B. Pollock, F.I. Rosell, M.B. Twitchett, M.E. Dumont, A.G. Mauk, Biochemistry 37 (1998) 6124-6131.

[18] C.N. Patel, M.C. Lind, G.J. Pielak, Protein Expression Purif. 22 (2001) 220-224.

[19] M.M. Cherney, C. Junior, B.E. Bowler, Biochemistry 52 (2013) 837-846.

[20] B.N. Hammack, C.R. Smith, B.E. Bowler, J. Mol. Biol. 311 (2001) 1091-1104.

[21] W.A. Eaton, R.M. Hochstrasser, J. Chem. Phys. 46 (1967) 2533-2539.

[22] I. Dragomir, A. Hagarman, C. Wallace, R. Schweitzer-Stenner, Biophys. J. 92 (2007) 989998.

[23] Z. Otwinowski, W. Minor, Methods Enzymol. 276A (1997) 307-326. 
[24] P.D. Adams, P.V. Afonine, G. Bunkóczi, V.B. Chen, I.W. Davis, N. Echols, J.J. Headd, L.W. Hung, G.J. Kapral, R.W. Grosse-Kunstleve, A.J. McCoy, N.W. Moriarty, R. Oeffner, R.J. Read, D.C. Richardson, J.S. Richardson, T.C. Terwilliger, P.H. Zwart, Acta Crystallogr., Sect. D: Biol. Crystallogr. 66 (2010) 213-221.

[25] P. Emsley, B. Lohkamp, W.G. Scott, K. Cowtan, Acta Crystallogr., Sect. D: Biol. Crystallogr. 66 (2010) 486-501.

[26] M.M. Krishna, Y. Lin, J.N. Rumbley, S.W. Englander, J. Mol. Biol. 331 (2003) 29-36.

[27] M.G. Duncan, M.D. Williams, B.E. Bowler, Protein Sci. 18 (2009) 1155-1164.

[28] Y. Xu, L. Mayne, S.W. Englander, Nat. Struct. Biol. 5 (1998) 774-778.

[29] M.M. Krishna, H. Maity, J.N. Rumbley, Y. Lin, S.W. Englander, J. Mol. Biol. 359 (2006) 1410-1419.

[30] L. Mayne, S.W. Englander, Protein Sci. 9 (2000) 1873-1877.

[31] J.A. Knapp, C.N. Pace, Biochemistry 13 (1974) 1289-1294.

[32] S. Godbole, B. Hammack, B.E. Bowler, J. Mol. Biol. 296 (2000) 217-228.

[33] M.M. Cherney, B.E. Bowler, Coord. Chem. Rev. 255 (2011) 664-677.

[34] M. Assfalg, I. Bertini, A. Dolfi, P. Turano, A.G. Mauk, F.I. Rosell, H.B. Gray, J. Am. Chem. Soc. 125 (2003) 2913-2922.

[35] J.F. Amacher, F. Zhong, G.P. Lisi, M.Q. Zhu, S.L. Alden, K.R. Hoke, D.R. Madden, E.V. Pletneva, J. Am. Chem. Soc. 137 (2015) 8435-8449.

[36] H. Maity, J.N. Rumbley, S.W. Englander, Proteins 63 (2006) 349-355.

[37] J.M. García-Heredia, A. Díaz-Quintana, M. Salzano, M. Orzáez, E. Pérez-Payá, M. Teixeira, M.A.D.1. Rosa, I. Díaz-Moreno, J. Biol. Inorg. Chem. 16 (2011) 1155-1168.

[38] J.M. García-Heredia, I. Díaz-Moreno, P.M. Nieto, M. Orzáez, S. Kocanis, M. Teixeira, E. Pérez-Payá, A. Díaz-Quintana, M.A.D.l. Rosa, Biochim. Biophys. Acta 1797 (2010) 981-993.

[39] T. Ying, F. Zhong, J. Xie, Y. Feng, Z.-H. Wang, Z.-X. Huang, X. Tan, J. Bioenerg. Biomembr. 41 (2009) 251-257.

[40] T.M. Josephs, M.D. Liptak, G. Hughes, A. Lo, R.M. Smith, S.M. Wilbanks, K.L. Bren, E.C. Ledgerwood, J. Biol. Inorg. Chem. 18 (2013) 289-297.

[41] B.S. Rajagopal, A.N. Edzuma, M.A. Hough, K.L.I.M. Blundell, V.E. Kagan, A.A. Kapralov, L.A. Fraser, J.N. Butt, G.G. Silkstone, M.T. Wilson, D.A. Svistunenko, J.A.R. Worrall, Biochem. J. 456 (2013) 441-452. 
[42] G. Battistuzzi, M. Borsari, A. Ranieri, M. Sola, Arch. Biochem. Biophys. 386 (2001) 117122.

[43] G. Battistuzzi, M. Borsari, L. Loschi, A. Martinelli, M. Sola, Biochemistry 38 (1999) 79007907.

[44] R.E. Martinez, B.E. Bowler, J. Am. Chem. Soc. 126 (2004) 6751-6758.

[45] D. Verbaro, A. Hagarman, J. Soffer, R. Schweitzer-Stenner, Biochemistry 48 (2009) 29902996.

[46] P. Weinkam, J. Zimmermann, L.B. Sagle, S. Matsuda, P.E. Dawson, P.G. Wolynes, F.E. Romesberg, Biochemistry 47 (2008) 13470-13480.

[47] G. Battistuzzi, M. Borsari, F. De Rienzo, G. Di Rocco, A. Ranieri, M. Sola, Biochemistry 46 (2007) 1694-1702.

[48] C. Blouin, J.G. Guillemette, C.J.A. Wallace, Biophys. J. 81 (2001) 2331-2338.

[49] R. Shah, R. Schweitzer-Stenner, Biochemistry 47 (2008) 5250-5257.

[50] Y. Hagihara, S. Aimoto, A. Fink, Y. Goto, J. Mol. Biol. 231 (1993) 180-184.

[51] C.J. Nelson, B.E. Bowler, Biochemistry 39 (2000) 13584-13594.

[52] G.D. Brayer, M.E.P. Murphy, in: R.A. Scott, A.G. Mauk (Eds.), Cytochrome c. A Multidisciplinary Approach, University Science Books, Sausalito, California, 1996, pp. 103-166.

[53] G.W. Bushnell, G.V. Louie, G.D. Brayer, J. Mol. Biol. 214 (1990) 585-595.

[54] T.P. Lo, S. Komar-Panucci, F. Sherman, G. McLendon, G.D. Brayer, Biochemistry 34 (1995) 5259-5268.

[55] R. Sanishvili, K.W. Volz, E.M. Westbrook, E. Margoliash, Structure 3 (1995) 707-717.

[56] A.M. Berghuis, G.D. Brayer, J. Mol. Biol. 223 (1992) 959-976.

[57] G.V. Louie, G.D. Brayer, J. Mol. Biol. 214 (1990) 527-555. 


\section{Figure Legends}

Fig. 1. Observed changes in corrected ellipticity, $\theta_{222 \mathrm{corr}}$, as a function of $\mathrm{GdnHCl}$ concentration for Hu Cyt $c$, SM Cyt $c$ and the set of variants required to convert Hu Cyt $c$ into SM Cytc. The solid lines are fits to Eq. (1) in section 2.4 of the Experimentals. Parameters from the fits to Eq. (1) are collected in Table 2. All data were obtained at $25{ }^{\circ} \mathrm{C}$ in $20 \mathrm{mM}$ Tris, $\mathrm{pH} 7,40 \mathrm{mM} \mathrm{NaCl}$.

Fig. 2. Alkaline conformational transition for $\mathrm{Hu}$ Cytc, SM Cytc and variants used to convert $\mathrm{Hu}$ to SM Cytc. Plots of $\mathrm{A}_{695 \text { corr }}$ versus $\mathrm{pH}$ are fit to Eq. (2) in the Experimentals (solid curves). Parameters from the fits to Eq. (2) are collected in Table 3. Data were obtained in $100 \mathrm{mM} \mathrm{NaCl}$ at $\sim 200 \mu \mathrm{M}$ protein concentration and at $23 \pm 1{ }^{\circ} \mathrm{C}$.

Fig. 3. Electron density around the heme of chain B of SM Cytc (pdb code: 5DFS) showing buried water (W 332 of chain B) with hydrogen bonds (yellow dashed lines) to the $-\mathrm{OH}$ of

Tyr67 (2.78 $\AA$ ), the side chain hydroxyl of Thr78 (2.67 $\AA$ ) and the carbonyl of the primary amide side chain of Asn52 (2.72 А).

Fig. 4. Overlay of chain A of Hu Cytc (gray, pdb code: 3ZCF, [41]) with chain A of SM Cytc (salmon, pdb code: 5DFS) showing the five side chain substitutions (stick models with red labels, for Lys8 of Hu Cytc, only one of two fitted side chain rotamers is shown) and the three buried water molecules (cyan spheres for Hu Cytc, red spheres for SM Cytc). The heme and the His18 and Met80 ligands and the side chains of Arg 38, Lys39, Gln42, Asn52, Lys53, Tyr67 and Thr78 are also shown as stick models (black labels). Buried waters are denoted with numbering from the pdb file for chain A of SM Cytc (black labels). Hydrogen bonds from the buried water 
(W 368) to Tyr67 (2.84 $)$, Thr78 (2.80 $)$ and Asn52 (3.03 $⿱$ ) and buried water (W334) to

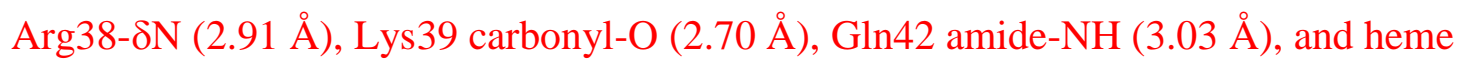
propionate A (2.66 ̊), are shown with black dashed lines.

Fig. 5. Close-up of changes in the hydrogen bond network around position 46 for Hu Cytc (Tyr 46, gray, chain A, pdb code: 3ZCF, [41]) and SM Cytc (Phe46, salmon, chain A, pdb code: 5DFS). Sites of sequence substitutions are labeled red. Other residues involved in the hydrogen bond network have black labels. Both positions of Lys79 in SM Cytc are labeled. Waters in the hydrogen bond network are shown as cyan (Hu Cytc) and red (SM Cytc) spheres. Hydrogen bonds (black dashed lines) for Hu Cytc have the following lengths: Lys79 $\varepsilon N$ to Ser47 carbonylO, $2.84 \AA$; Lys79 عN to water $2100,2.76 \AA$; W2100 to W2043, $2.63 \AA$; W2043 to Thr28 carbonyl-O, $2.74 \AA$ А; Tyr46-OH to Thr28 carbonyl-O, $2.63 \AA$. Hydrogen bonds (magenta dashed lines) for SM Cytc have the following lengths: Lys79 $\varepsilon N$ to Thr47 carbonyl-O, $2.76 \AA$; Lys79 $\varepsilon N$ to heme propionate D, $3.05 \AA$; water 362 to Thr28 carbonyl-O, $2.79 \AA$.

Fig. 6. Effect of $\mathrm{Cl}^{-}$binding on electrostatic networks in SM Cytc. (A) Molecule B of SM Cytc (pdb code: 5DFS) showing electrostatic contacts (magenta dashed lines) of $\sim 5 \AA$ or less (distances given in black type) in the absence of $\mathrm{Cl}^{-}$binding. The dominant conformer (63\% occupancy) of Arg91 is shown. The other conformer of Arg91 forms a shorter hydrogen bond of $2.72 \AA$ to the main chain carbonyl of Lys86. (B) Molecule A of SM Cytc (pdb code: 5DFS) showing electrostatic contacts (magenta dashed lines) of $\sim 5 \AA$ or less (distances given in black type) in the presence of $\mathrm{Cl}^{-}$binding. $\mathrm{Cl}^{-}$ions are shown as green spheres. The dominant conformer of $\operatorname{Arg} 91$ (83\% occupancy) is shown. The minor conformer of Arg91 forms a $2.78 \AA$ 
hydrogen bond with the main chain carbonyl of Lys86. In both panels residues are labeled in red using one letter amino acids abbreviations and the $\mathrm{N}$-terminal amino group is labeled $\mathrm{N}$-term. 
Table 1

X-ray crystallography data collection and refinement statistics.

\begin{tabular}{|c|c|}
\hline Beamline & 14.1 \\
\hline Wavelength $(\AA)$ & 1.22 \\
\hline Resolution range $(\AA)$ & $\begin{array}{l}15.0-1.15 \\
(1.19-1.15)^{\mathrm{a}}\end{array}$ \\
\hline Space group & $\mathrm{P} 2{ }_{1}$ \\
\hline $\begin{array}{l}\text { Unit cell dimensions } \\
\qquad \mathrm{a}, \mathrm{b}, \mathrm{c}(\AA) \\
\quad \alpha, \beta, \gamma\left({ }^{\circ}\right)\end{array}$ & $\begin{array}{l}31.5,42.7,65.7 \\
90,94.5,90\end{array}$ \\
\hline Total reflections & 172044 \\
\hline Unique reflections & $62439(6168)$ \\
\hline Multiplicity & $2.8(2.7)^{\mathrm{a}}$ \\
\hline Completeness (\%) & $97.8(97.6)^{\mathrm{a}}$ \\
\hline Mean $I / \sigma(I)$ & $15.4(2.05)^{\mathrm{a}}$ \\
\hline Wilson B-factor & 9.30 \\
\hline $\mathrm{R}_{\text {sym }}^{\mathrm{b}}$ & $0.065(0.615)^{\mathrm{a}}$ \\
\hline \multicolumn{2}{|l|}{ Refinement } \\
\hline $\mathrm{R}_{\text {work }}^{\mathrm{c}}$ & $0.159(0.241)^{\mathrm{a}}$ \\
\hline $\mathrm{R}_{\text {free }}^{\mathrm{c}}$ & $0.182(0.249)^{\mathrm{a}}$ \\
\hline Number of total atoms & 2099 \\
\hline protein molecule & 1679 \\
\hline ligands & 112 \\
\hline water & 308 \\
\hline Total protein residues & 208 \\
\hline RMS (bonds, Å) & 0.018 \\
\hline RMS (angles, $\circ$ ) & 1.64 \\
\hline Ramachandran favored $(\%)^{\mathrm{d}}$ & 98 \\
\hline Rotamer outliers $(\%)$ & 0 \\
\hline Average B-factor & 14.50 \\
\hline macromolecules & 13.10 \\
\hline ligands & 11.10 \\
\hline solvent & 23.40 \\
\hline
\end{tabular}

${ }^{\mathrm{a}}$ Data for highest resolution shell are given in brackets.

${ }^{\mathrm{b}} R_{s y m}=\sum_{h k l} \sum_{i}\left|I_{i}(h k l)-\langle I(h k l)\rangle\right| / \sum_{h k l} \sum_{i} I_{i}(h k l)$ where $I_{i}(h k l)$ is the $i^{\text {th }}$ observation of the intensity of the reflection $h k l$.

${ }^{\mathrm{c}} \mathrm{R}_{\text {work }}=\sum_{h k l}|| F_{o b s}|-| F_{c a l c}|| / \sum_{h k l}\left|F_{o b s}\right|$, where $F_{o b s}$ and $F_{\text {calc }}$ are the observed and calculated structure-factor amplitudes for each reflection $h \mathrm{kl}$. $\mathrm{R}_{\text {free }}$ was calculated with $6 \%$ of the diffraction data that were selected randomly and excluded from refinement.

${ }^{\mathrm{d}}$ Calculated using MolProbity (Chen et al., 2010). 


\section{Table 2}

Global stability parameters from $\mathrm{GdnHCl}$ denaturation of Cytc variants at $25^{\circ} \mathrm{C}$ and $\mathrm{pH} 7$.

\begin{tabular}{lccc}
\hline Variant & $\Delta \mathrm{G}_{\mathrm{u}}^{\circ}\left(\mathrm{H}_{2} \mathrm{O}\right)$ & $m$ & $\mathrm{C}_{\mathrm{m}}$ \\
\hline Human & $8.9 \pm 0.2$ & $3.51 \pm 0.06$ & $2.54 \pm 0.01$ \\
K8R & $9.0 \pm 0.1$ & $3.48 \pm 0.04$ & $2.58 \pm 0.04$ \\
K8R/P44S & $8.8 \pm 0.2$ & $3.52 \pm 0.11$ & $2.51 \pm 0.02$ \\
K8R/P44S/Y46F & $8.7 \pm 0.2$ & $3.44 \pm 0.17$ & $2.52 \pm 0.06$ \\
K8R/P44S/Y46F/S47T & $9.0 \pm 0.1$ & $3.66 \pm 0.03$ & $2.45 \pm 0.01$ \\
K8R/P44S/Y46F/S47T/A50E & $8.7 \pm 0.4$ & $3.49 \pm 0.19$ & $2.48 \pm 0.02$ \\
(Spider Monkey) & 7.27 & & \\
Equine $^{\mathrm{a}}$ & 8.38 & 3.01 & 2.42 \\
Bovine $^{\mathrm{a}}$ & $5.77 \pm 0.4$ & $5.11 \pm 0.36$ & $1.13 \pm 0.02$ \\
Yeast $^{\mathrm{b}}$ & & 3.19 & 2.62 \\
\hline
\end{tabular}

${ }^{\mathrm{a}}$ At $25^{\circ} \mathrm{C}$ and $\mathrm{pH}$ 6.5. Data are from Ref. [31]

${ }^{\mathrm{b}}$ At $25^{\circ} \mathrm{C}$ and $\mathrm{pH}$ 7.5. See ref. [32]. 


\section{Table 3}

Parameters for the alkaline conformational transition of Cyt $c$ at $23 \pm 1{ }^{\circ} \mathrm{C}$ in $0.1 \mathrm{M} \mathrm{NaCl}$ solution.

\begin{tabular}{lcc}
\hline Variant & $\mathrm{p} K_{\text {app }}$ & $n$ \\
\hline Human & $9.54 \pm 0.03$ & $1.03 \pm 0.02$ \\
K8R & $9.63 \pm 0.07$ & $1.02 \pm 0.06$ \\
K8R/P44S & $9.51 \pm 0.05$ & $1.06 \pm 0.06$ \\
K8R/P44S/Y46F & $9.15 \pm 0.02$ & $0.93 \pm 0.02$ \\
K8R/P44S/Y46F/S47T & $9.05 \pm 0.01$ & $0.90 \pm 0.05$ \\
Spider Monkey & $9.32 \pm 0.03$ & $0.87 \pm 0.01$ \\
\hline
\end{tabular}

\section{Table 4}

Parameters for the alkaline conformational transition of SM Cytc at $23 \pm 1{ }^{\circ} \mathrm{C}$ as a function of solution ionic strength.

\begin{tabular}{lccc}
\hline Ionic Strength $^{\mathrm{a}}$ & \multicolumn{2}{l}{$\begin{array}{l}\text { Spider Monkey } \\
(\text { E. Coli-expressed) }\end{array}$} & $\begin{array}{c}\text { Spider Monkey } \\
\text { (Natural Source) }^{\mathrm{b}}\end{array}$ \\
\hline $10 \mathrm{mM}^{\mathrm{c}}$ & $9.21 \pm 0.03$ & $0.79 \pm 0.04$ & $\mathrm{p} K_{\text {app }}$ \\
$50 \mathrm{mM}$ & $9.15 \pm 0.05$ & $0.78 \pm 0.01$ & $8.70 \pm 0.05$ \\
$250 \mathrm{mM}$ & $9.22 \pm 0.02$ & $0.89 \pm 0.05$ & - \\
\hline
\end{tabular}

${ }^{\mathrm{a}}$ Ionic strength adjusted with $\mathrm{NaCl}$ in the presence of $10 \mathrm{mM}$ Tris acetate

${ }^{\mathrm{b}}$ Values from ref. [15]. Values of $n$ not reported individually, a range of 0.8 to 1.1

was indicated. $10 \mathrm{mM}$ value was obtained in the presence of Tris acetate. Ionic strength for $250 \mathrm{mM}$ was adjusted with sodium acetate.

${ }^{\mathrm{c}} 10 \mathrm{mM}$ Tris acetate, no $\mathrm{NaCl}$ added. 
Figure 1

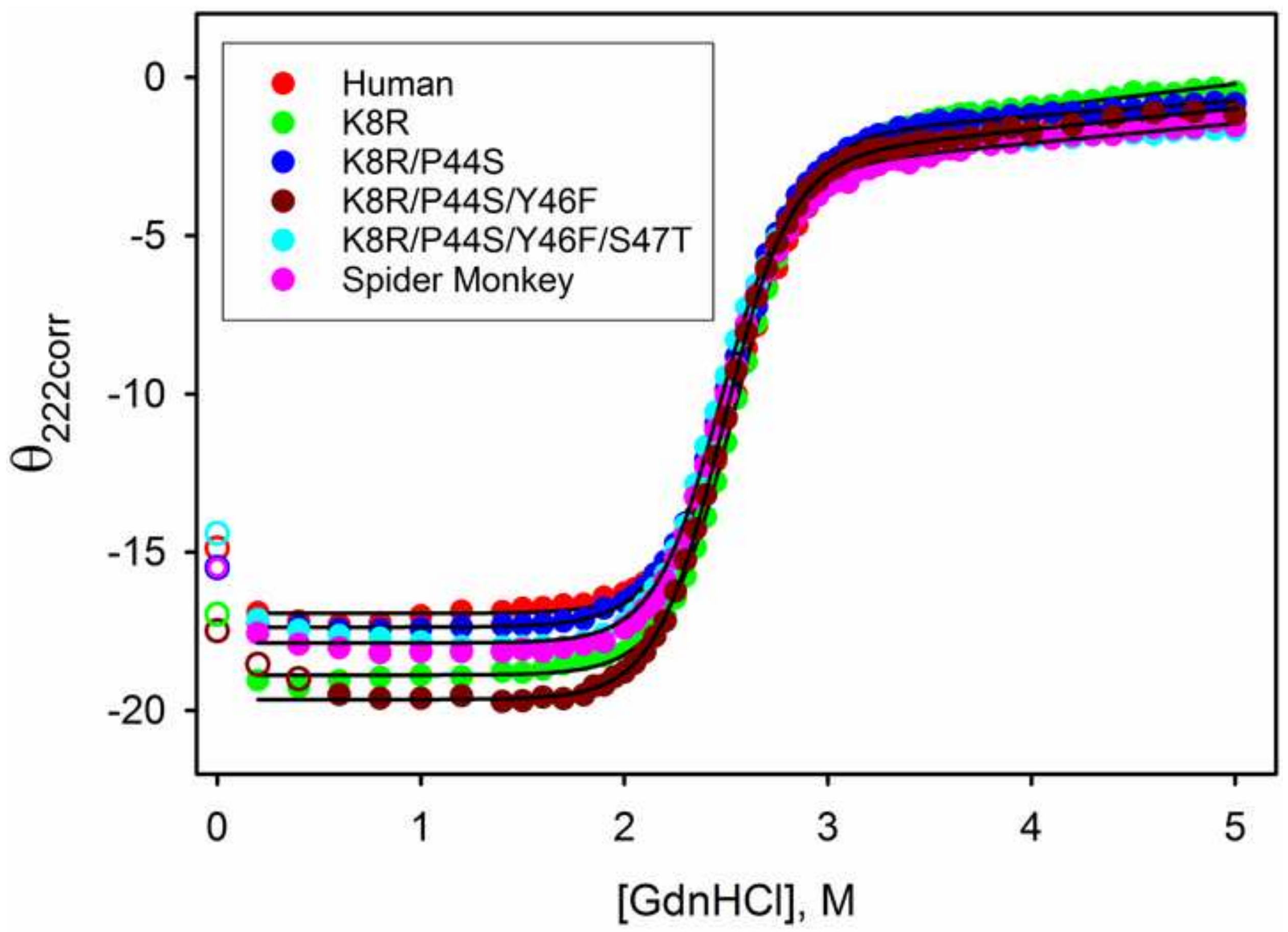




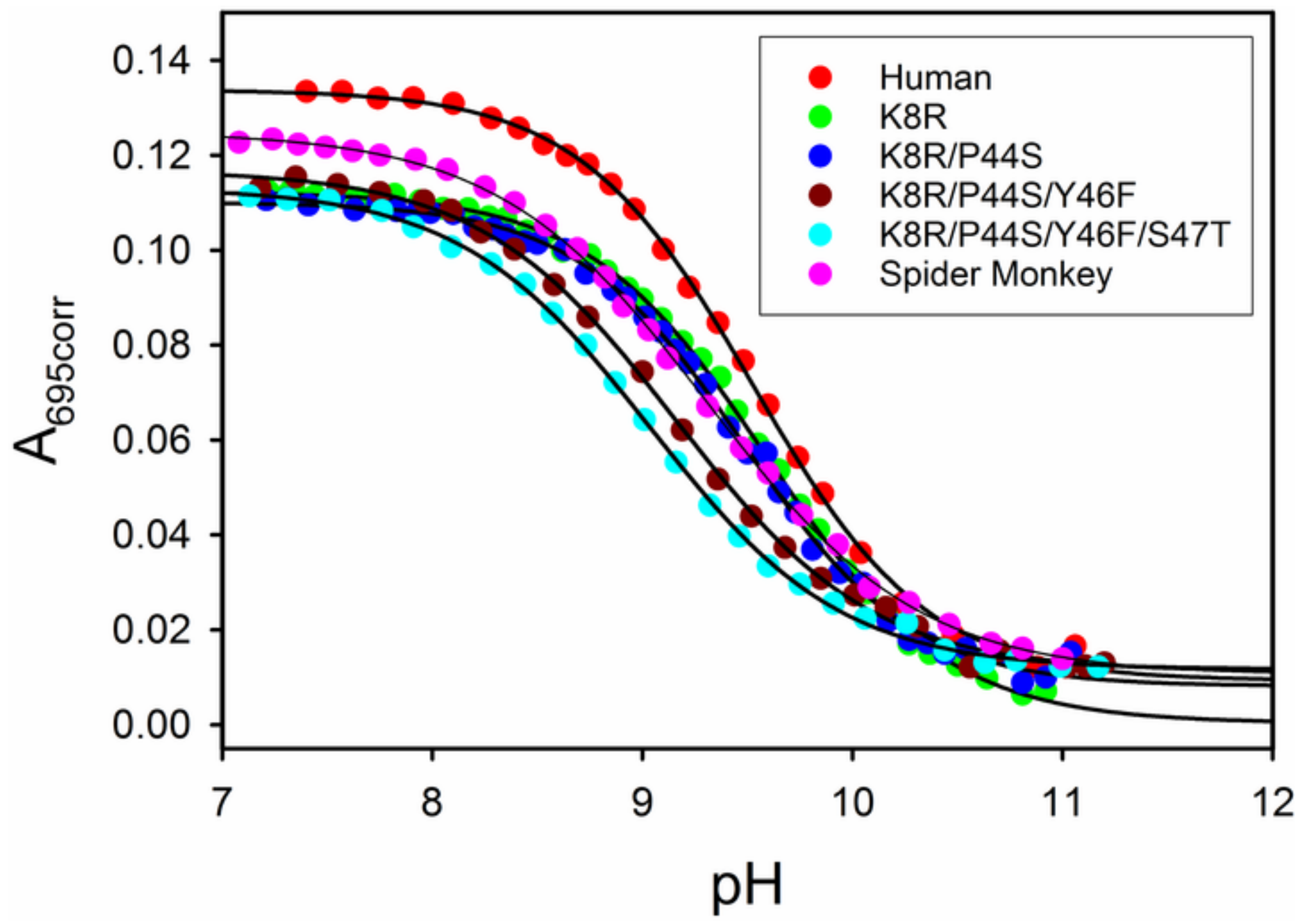




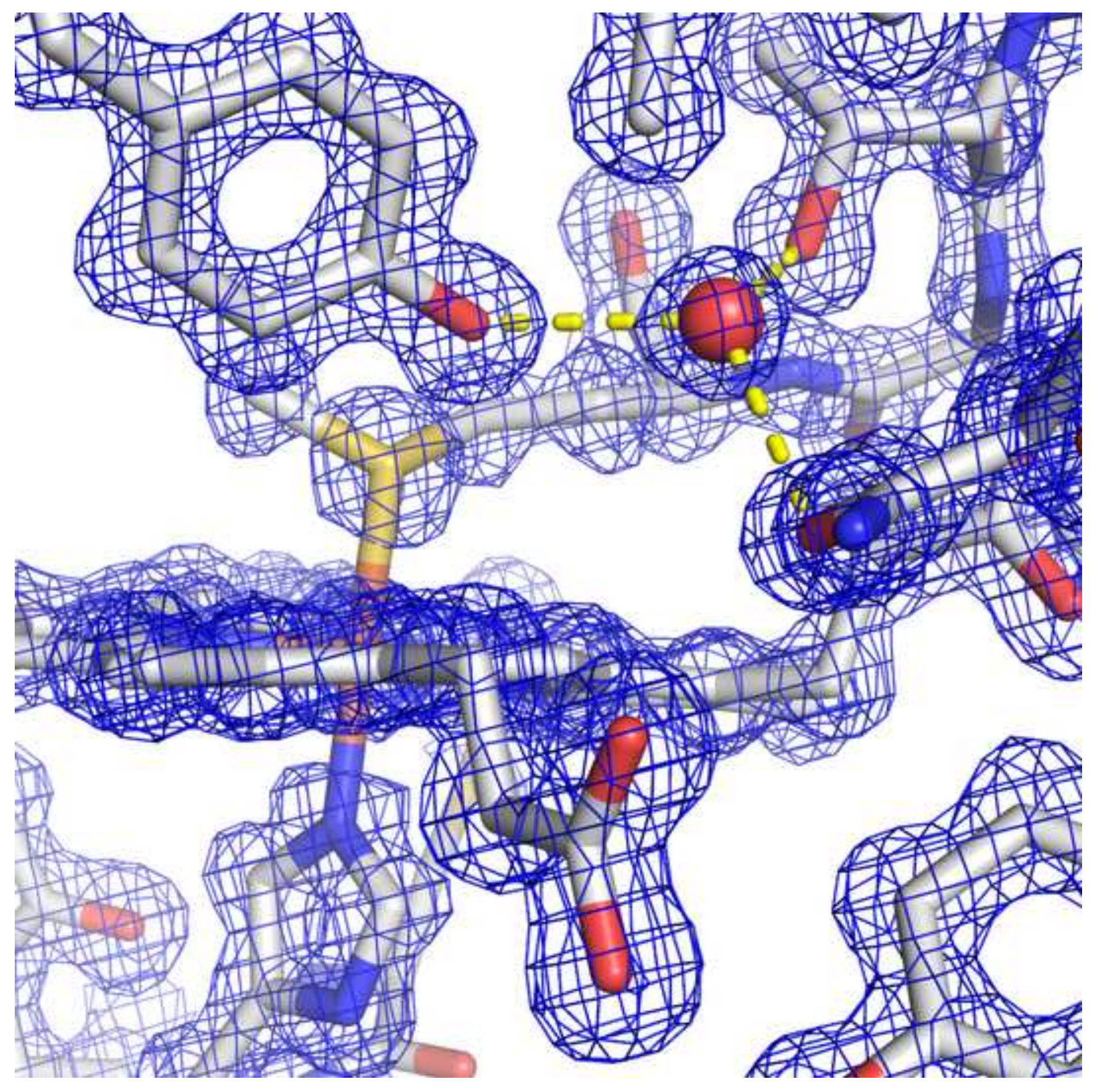




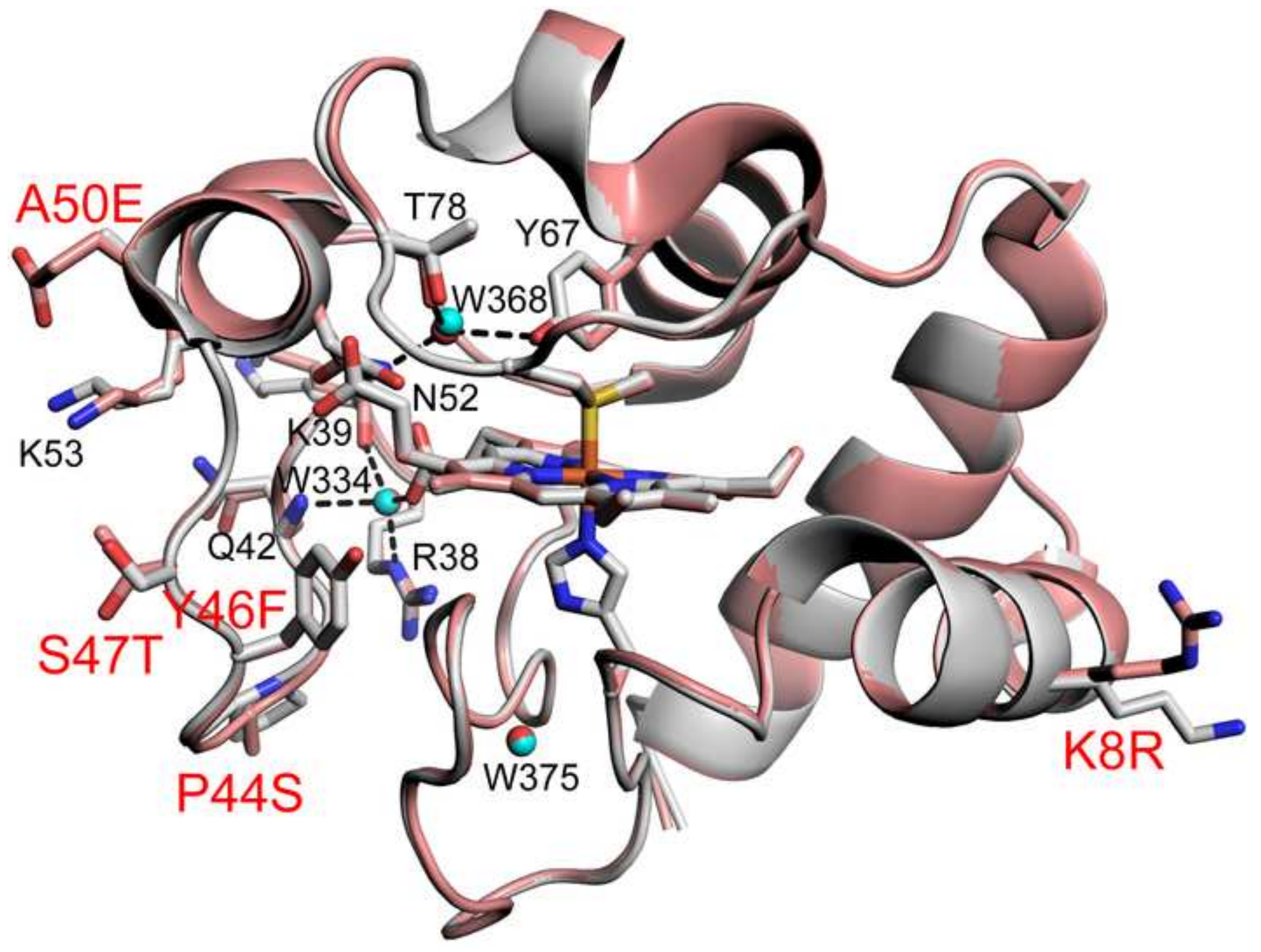


Figure 5

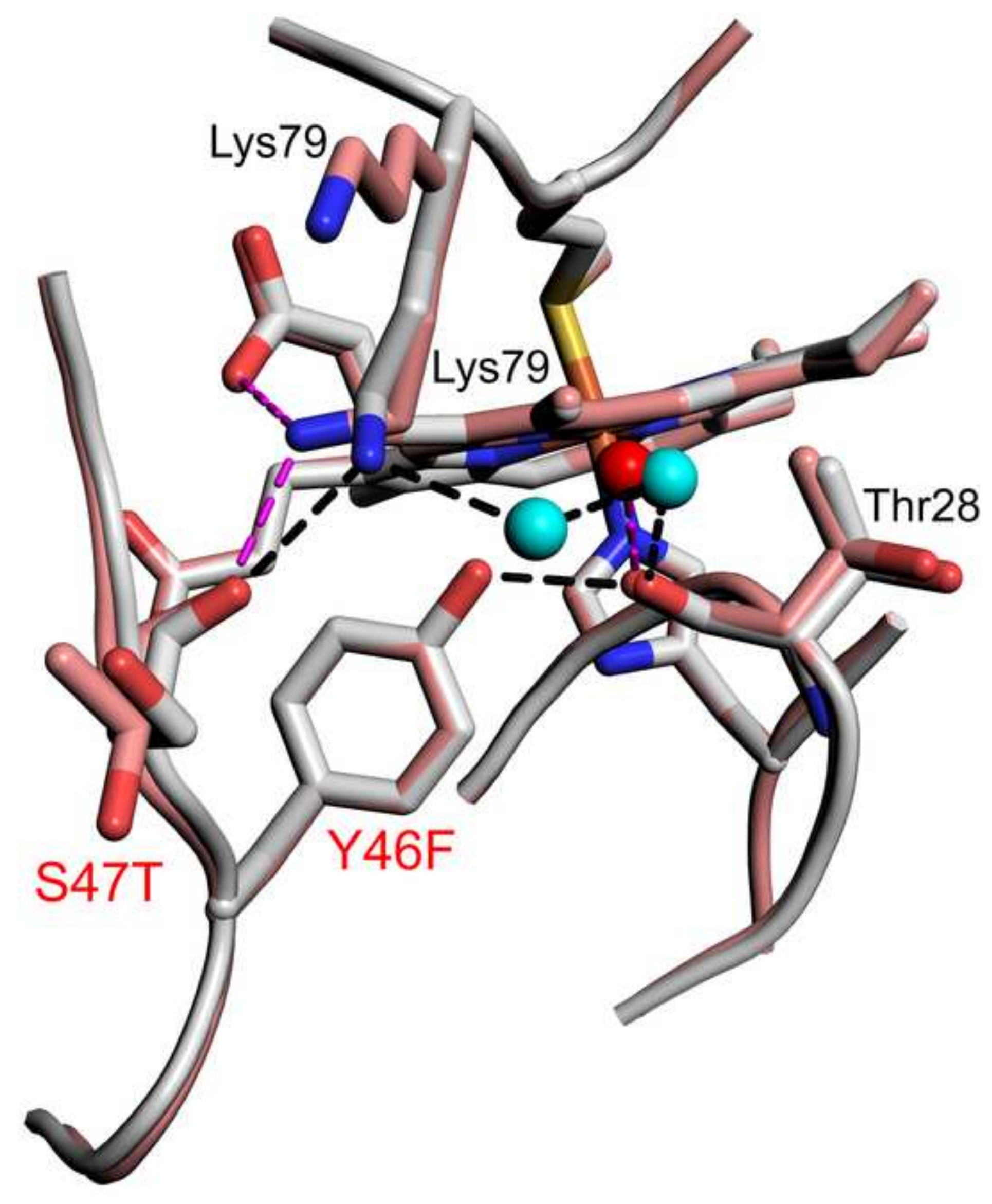


Figure 6
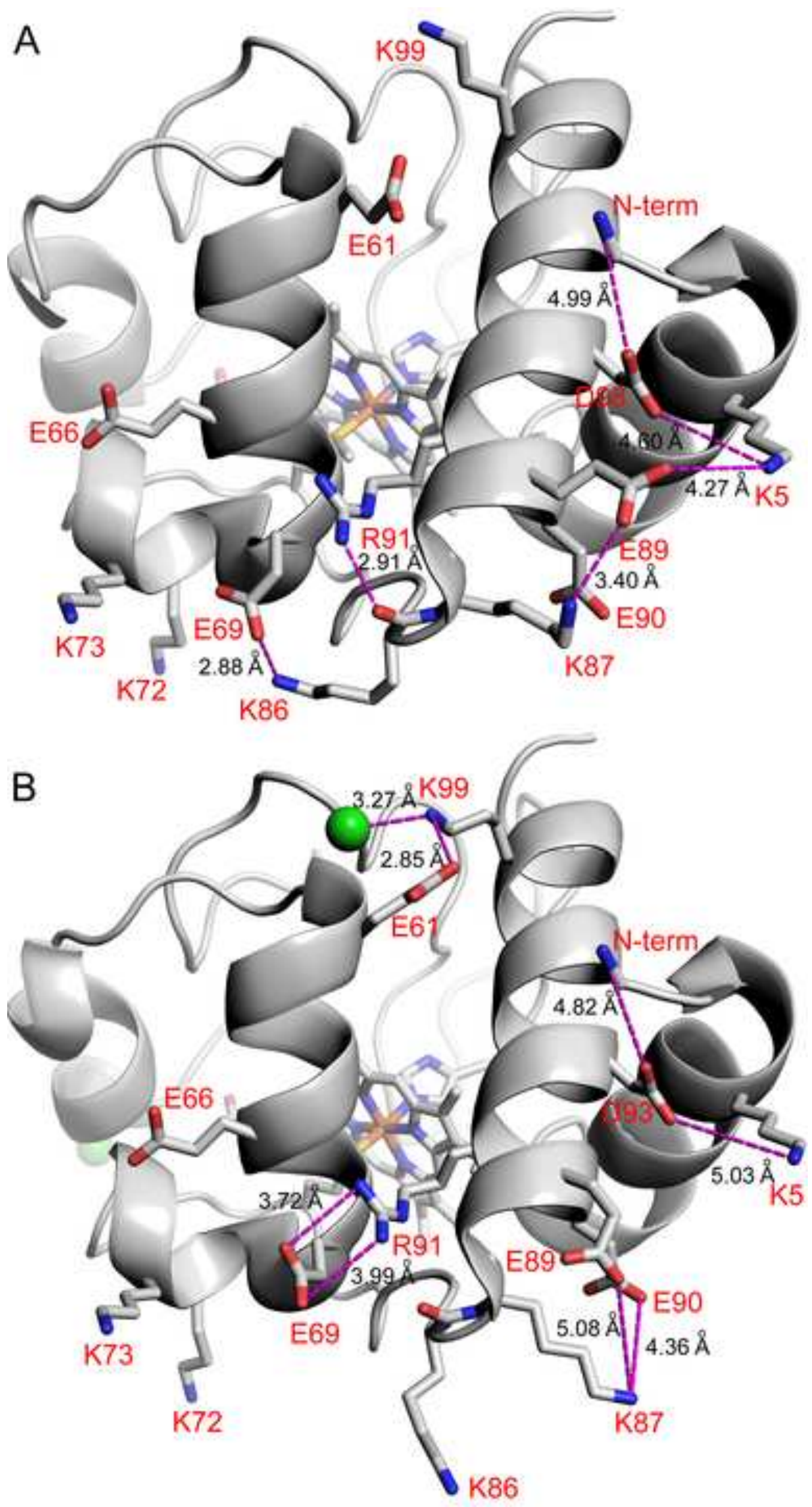
Pictogram for the Graphical Abstract

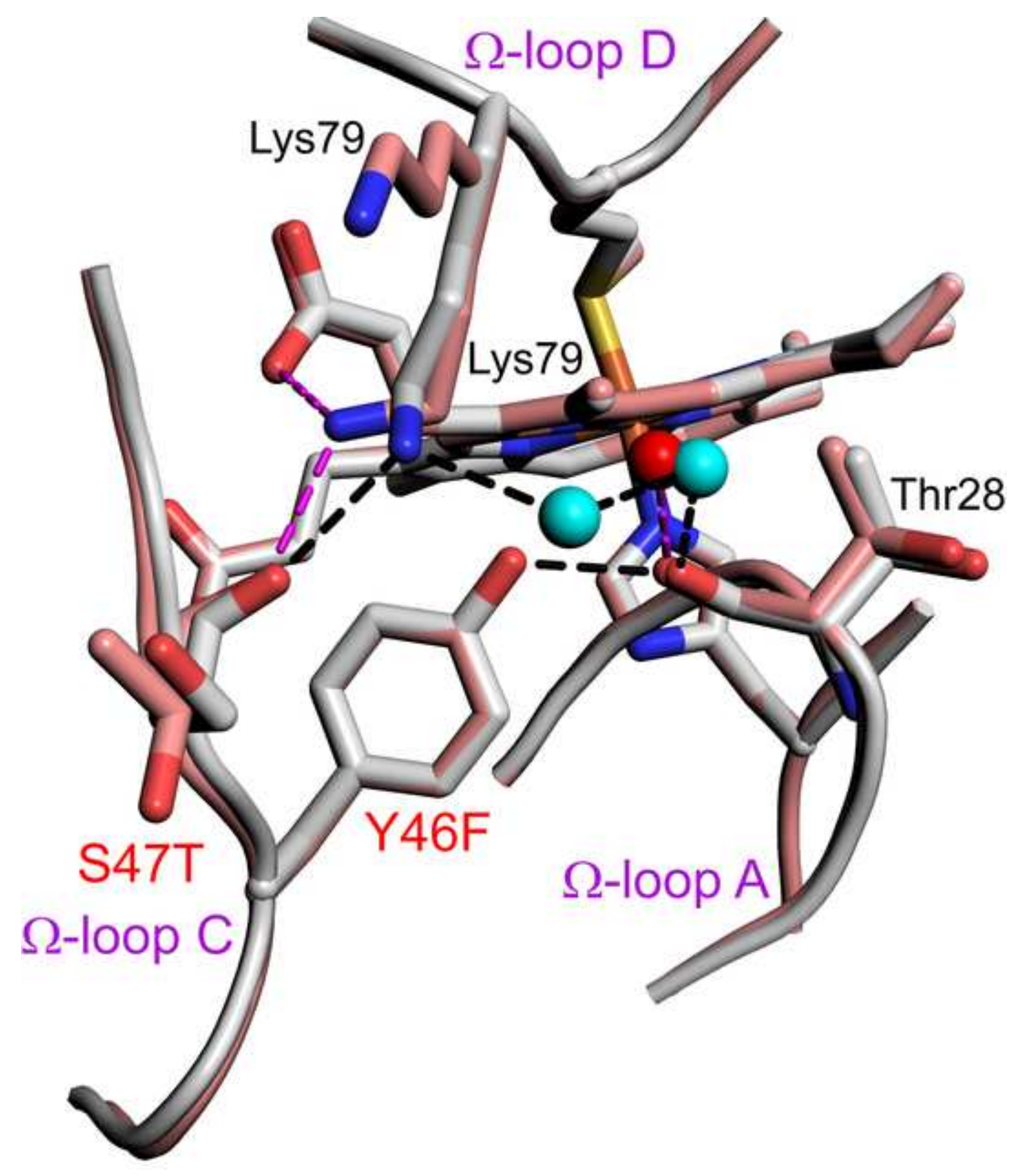




\section{Graphical Abstract:}

Destabilization of the heme crevice during the rapid evolution of primate cytochromes $c$ is primarily due to a Y46F substitution, which disrupts of a hydrogen bond network that knits together three surface $\Omega$-loops. 